\title{
Superoxide-mediated activation of uncoupling protein 2 causes pancreatic $\beta$ cell dysfunction
}

\author{
Stefan Krauss, ${ }^{1}$ Chen-Yu Zhang, ${ }^{1}$ Luca Scorrano, ${ }^{2}$ Louise T. Dalgaard, ${ }^{1}$ Julie St-Pierre, ${ }^{3}$ \\ Shane T. Grey, ${ }^{4}$ and Bradford B. Lowell ${ }^{1}$ \\ ${ }^{1}$ Division of Endocrinology, Department of Medicine, Beth Israel Deaconess Medical Center and Harvard Medical School, \\ Boston, Massachusetts, USA \\ ${ }^{2}$ Department of Cancer Immunology and AIDS, and \\ ${ }^{3}$ Department of Cancer Biology, Dana-Farber Cancer Institute and Harvard Medical School, Boston, Massachusetts, USA \\ ${ }^{4}$ Department of Surgery, Beth Israel Deaconess Medical Center and Harvard Medical School, Boston, Massachusetts, USA
}

\begin{abstract}
Failure to secrete adequate amounts of insulin in response to increasing concentrations of glucose is an important feature of type 2 diabetes. The mechanism for loss of glucose responsiveness is unknown. Uncoupling protein 2 (UCP2), by virtue of its mitochondrial proton leak activity and consequent negative effect on ATP production, impairs glucose-stimulated insulin secretion. Of interest, it has recently been shown that superoxide, when added to isolated mitochondria, activates UCP2-mediated proton leak. Since obesity and chronic hyperglycemia increase mitochondrial superoxide production, as well as UCP2 expression in pancreatic $\beta$ cells, a superoxide-UCP2 pathway could contribute importantly to obesity- and hyperglycemia-induced $\beta$ cell dysfunction. This study demonstrates that endogenously produced mitochondrial superoxide activates UCP2-mediated proton leak, thus lowering ATP levels and impairing glucose-stimulated insulin secretion. Furthermore, hyperglycemia- and obesity-induced loss of glucose responsiveness is prevented by reduction of mitochondrial superoxide production or gene knockout of UCP2. Importantly, reduction of superoxide has no beneficial effect in the absence of UCP2, and superoxide levels are increased further in the absence of UCP2, demonstrating that the adverse effects of superoxide on $\beta$ cell glucose sensing are caused by activation of UCP 2 . Therefore, superoxide-mediated activation of UCP2 could play an important role in the pathogenesis of $\beta$ cell dysfunction and type 2 diabetes.
\end{abstract}

J. Clin. Invest. 112:1831-1842 (2003). doi:10.1172/JCI200319774.

\section{Introduction}

$\beta$ Cell dysfunction together with insulin resistance, causes type 2 diabetes. Dysfunction of $\beta$ cells is a complex

Received for publication August 11, 2002, and accepted in revised form September 30, 2003.

Address correspondence to: Bradford B. Lowell, Beth Israel Deaconess Medical Center, Research North RN-325, 99 Brookline Avenue, Boston, Massachusetts 02215, USA. Phone: (617) 667-5954; Fax: (617) 667-2927;

E-mail: blowell@bidmc.harvard.edu.

Luca Scorrano's present address is: Dulbecco Telethon Institute, Venetian Institute of Molecular Medicine, Padova, Italy.

Shane T. Grey's present address is: Arthritis and Inflammation Program, Garvan Institute of Medical Research, Darlinghurst, New South Wales, Australia.

Stefan Krauss and Chen-Yu Zhang contributed equally to this work.

Conflict of interest: The authors have declared that no conflict of interest exists.

Nonstandard abbreviations used: glucose-stimulated insulin secretion (GSIS); uncoupling protein (UCP); reactive oxygen species (ROS); triphenylmethylphosphonium cation (TPMP ${ }^{+}$); ${ }^{3} \mathrm{H}$-labeled triphenylmethylphosphonium $\left(\left[{ }^{3} \mathrm{H}\right] \mathrm{TPMP}{ }^{+}\right)$;

$\mathrm{Mn}(\mathrm{III})$ tetrakis(4-benzoic acid)porphyrin (MnTBAP); tetramethyl rhodamine methyl ester (TMRM); tetramethylrhodamine methyl ester (TMRM); carbonyl cyanide 4-trifluoromethoxy-

phenylhydrazone (FCCP); manganese superoxide dismutase

(MnSOD); glutathione peroxidase (GPX1);

Zucker diabetic fatty (ZDF). phenomenon that includes loss of glucose sensing, resulting in impairment of glucose-stimulated insulin secretion (GSIS); increased basal insulin secretion; decreased islet insulin content; altered gene transcription; changes in intracellular signaling intermediates; and loss of $\beta$ cell mass (1-3). While the loss of GSIS plays an important pathophysiological role in development of $\beta$ cell dysfunction, the precise mechanisms for the progressive loss of glucose sensing are not fully understood.

Uncoupling protein 2 (UCP2) is a negative regulator of insulin secretion. It mediates proton leak across the inner mitochondrial membrane. This has been demonstrated in studies using proteoliposomes $(4,5)$ and isolated mitochondria (6) and in intact cells (7). In pancreatic $\beta$ cells, UCP2-mediated proton leak decreases the yield of ATP from glucose $(8,9)$. Consequently, UCP2 negatively regulates GSIS $(8,9)$. UCP2 is markedly upregulated in islets of $o b / o b$ mice, a model of obesity-induced diabetes (8). Also, it has been shown that UCP2 levels in islets are increased by hyperglycemia (10, 11). Of note, gene knockout of UCP2 restores firstphase insulin secretion, increases serum insulin levels, and greatly decreases levels of glycemia in $o b / o b$ mice (8). Taken together, these findings indicate that UCP2 could be an important mediator of hyperglycemia- and obesity-induced $\beta$ cell dysfunction. 
To date, it is unknown whether and how UCP2 activity is acutely regulated inside cells. Recently, it was shown that a particular reactive oxygen species (ROS), superoxide, when added to isolated mitochondria, activated UCP2 and its homologs UCP1 and UCP3 (6). However, it was unknown from this study whether naturally generated superoxide, at physiological levels, would acutely regulate UCP2 activity. Of interest, it has been shown that increased glucose concentrations increase ROS production in various cell types (12-15) including islets $(16,17)$. Since elevated glucose levels are also known to increase UCP2 protein in islets $(10,11)$, it is possible that, under hyperglycemic conditions and/or in the obese state, UCP2 activity increases greatly in response to increased superoxide production. If this is true, superoxide-mediated UCP2 activation could be an important cause of hyperglycemia- and obesityinduced $\beta$ cell dysfunction. In the present study, we assessed the importance of this superoxide-UCP2 pathway in regulating mitochondrial proton leak, ATP production, and insulin secretion and in causing hyperglycemia- and obesity-induced $\beta$ cell dysfunction.

\section{Methods}

\section{Isolation of mitochondria}

WT and UCP2-deficient mice were used (8) for isolation of kidney and spleen mitochondria. Per experiment, 15 mice were used for isolation of mitochondria from spleen, and five mice were used for isolation of kidney mitochondria. Fresh tissues were minced in icecold STE buffer $(250 \mathrm{mM}$ sucrose, $5 \mathrm{mM}$ Tris, $2 \mathrm{mM}$ EGTA, pH 7.4 at $4^{\circ} \mathrm{C}$ ) and disrupted in a Dounce homogenizer. Cell debris was removed by centrifugation of the homogenate at $500 \mathrm{~g}$ for 3 minutes. The supernatant was centrifuged at $10,000 \mathrm{~g}$ for 8 minutes, and the mitochondrial pellet was resuspended in icecold STE buffer. Mitochondria were subjected to another cycle of centrifugation at 750 and $10,000 \mathrm{~g}$. Protein content was assayed using the bicinchoninic acid method. Western blot analysis of UCP2 expression in kidney mitochondria was performed as described previously (8).

Proton leak titrations in mitochondria

Mitochondria (0.35 mg mitochondrial protein $/ \mathrm{ml}$ for kidney, $0.6 \mathrm{mg} / \mathrm{ml}$ for spleen) were incubated in $\mathrm{KHE}$ assay medium $\left(120 \mathrm{mM} \mathrm{KCl}, 5 \mathrm{mM} \mathrm{KH}{ }_{2} \mathrm{PO}_{4}, 3\right.$ mM HEPES, 1 mM EGTA, pH 7.2) with $1 \mu \mathrm{g} / \mathrm{ml}$ oligomycin to block protons from re-entering the mitochondrial matrix via ATP synthase (6). Potential was varied by titration with submaximal doses of malonate (in $170-\mu \mathrm{M}$ increments). Rotenone was added $(5 \mu \mathrm{M})$ to prevent oxidation of any endogenous NAD-linked substrates. Nigericin $(80 \mathrm{ng} / \mathrm{ml})$ was added to abolish the $\mathrm{pH}$ gradient. Using succinate as a substrate $(4 \mathrm{mM})$, respiration rate and membrane potential were measured simultaneously using electrodes sensitive to oxygen and the potential-sen- sitive probe triphenylmethyl phosphonium cation $\left(\mathrm{TPMP}^{+}\right)$. Oxygen-consumption rates were multiplied by the $\mathrm{H}^{+} / \mathrm{O}$ ratio of 6 to yield proton leak rates.

Measurement of oxygen consumption and mitochondrial membrane potential in intact cells

Proton leak was determined in intact thymocytes by concomitant measurement of nonphosphorylating oxygen consumption at different levels of mitochondrial membrane potential as described previously $(7,18)$. Thymocytes were incubated with $160 \mathrm{ng} / \mathrm{ml}$ oligomycin to block ATP synthase activity, and 0 or $80 \mathrm{nM}$ myxothiazol to inhibit electron transport. The potential-sensitive probe ${ }^{3} \mathrm{H}$-labeled triphenylmethyl phosphonium $\left(\left[{ }^{3} \mathrm{H}\right] \mathrm{TPMP}^{+}\right)(\mathrm{NEN}$ Life Science Products Inc., Boston, Massachusetts, USA) and carriers $\left(\mathrm{TPMP}^{+}\right.$and tetraphenylboron) were added as described previously (18). Thirty micromolar Mn(III)tetrakis(4-benzoic acid)porphyrin (MnTBAP; Calbiochem-Novabiochem Corp., San Diego, California, USA) was added at the beginning of the incubation when appropriate. Mitochondrial membrane potential was calculated as described previously (18). Proton leak rates were calculated by multiplication of rates of oxygen consumption by the $\mathrm{H}^{+} / \mathrm{O}$ ratio of 9 (for cells respiring on glutamine).

\section{Assessment of energy metabolism in thymocytes}

Mitochondrial membrane potential, ATP levels, and oxygen consumption in resting thymocytes were measured as described above (except that no inhibitors were added to cells) and in ref. 19.

Preparation of dispersed islet cells and tetramethylrhodamine methyl ester imaging

Islets of Langerhans were isolated from WT or UCP2deficient mice using collagenase digestion as described previously (8). Islets were dissociated by incubation in $0.5 \%$ trypsin/5.3 mM EDTA for 20 minutes at room temperature. Islet cells were washed twice in RPMI medium (11 mM glucose, supplemented with $7.5 \%$ FCS and $1 \%$ penicillin-streptomycin) and spotted onto glass coverslips that had been precoated with a solution of $0.1 \%$ collagen in 0.1 $\mathrm{M}$ acetic acid. The cells were then maintained overnight in RPMI medium. To study mitochondrial membrane potential, tetramethylrhodamine methyl ester (TMRM) imaging and analysis were carried out essentially as described previously (20), except that cells were loaded with 10 nM TMRM (Molecular Probes Inc., Eugene, Oregon, USA) for 30 minutes, and images were acquired every 15 seconds with an exposure time of 60 milliseconds. Addition of oligomycin $(1 \mu \mathrm{g} / \mathrm{ml})$ or carbonyl cyanide 4-trifluoromethoxyphenylhydrazone (FCCP) $(2 \mu \mathrm{M})$ induced the expected changes in mitochondrial TMRM fluorescence, i.e., an increase to $143 \% \pm 3.2 \%$ and a decrease to $23 \% \pm 1.2 \%$ of the initial value, respectively. No significant difference was noted between WT and UCP2-deficient cells. 


\section{Islet mitochondrial membrane potential}

Mitochondrial membrane potential was estimated from $\left[{ }^{3} \mathrm{H}\right] \mathrm{TPMP}^{+}$accumulation experiments as described previously (19). A subset of islets used for mitochondrial membrane potential measurements was transduced overnight (100,000 PFUs per islet) with an adenovirus that drives expression of manganese superoxide dismutase (MnSOD) and glutathione peroxidase (GPX1) as described previously $(21,22)$. Adenoviruses were purchased from the Gene Transfer Vector Core of the University of Iowa (Iowa City, Iowa, USA). Islets were incubated for 30 minutes in RPMI medium (11 mM glucose, supplemented with $7.5 \%$ FCS and $1 \%$ penicillin-streptomycin) with $0.1 \mu \mathrm{Ci}\left[{ }^{3} \mathrm{H}\right] \mathrm{TPMP}^{+}$and carriers $(0.2 \mu \mathrm{M}$ $\mathrm{TPMP}^{+}$and $1.5 \mu \mathrm{M}$ tetraphenylboron), and $\left.{ }^{3} \mathrm{H}\right] \mathrm{TPMP}^{+}$ accumulation and mitochondrial membrane potential were calculated as described previously (19).

\section{Islet ATP and insulin secretion}

Islets were isolated as above and incubated overnight in RPMI 1640 (11 mM glucose, supplemented with 7.5\% FCS and $1 \%$ penicillin-streptomycin). This procedure greatly decreases the granular pool of ATP in islets, which has been shown to mask changes in the $\mathrm{ATP} / \mathrm{ADP}$ ratio during glucose sensing $(23,24)$. On the next day, islets were transferred into DMEM $(5.5 \mathrm{mM}$ glucose plus $0.1 \%$ gelatin). A subset of islets was transduced overnight (100,000 PFUs per islet) with adenovirus driving expression of MnSOD, GPX1, and GFP as described previously $(21,22)$. MnTBAP $(0,10$, or 20 $\mu \mathrm{M}$ as indicated) was added to another subset of islets 1 hour before sampling for insulin and ATP. Islets were transferred to DMEM, and ATP levels were determined as described previously (8). Insulin levels in the medium were determined as described previously (8) except that a rat-insulin ELISA kit (Crystal Chem Inc., Chicago, Illinois, USA) was used. For determination of islet insulin content and islet DNA, 30 islets were separated from each of the different subsets of islets (e.g., islets overexpressing MnSOD, or treated with MnTBAP) before insulin measurements were started. Fifteen islets were homogenized and lysed with lysate buffer (25), and sonicated for 45 seconds. Homogenates were left on ice for at least 30 minutes, mixed, and spun at $16,000 \mathrm{~g}$ in an Eppendorf bench centrifuge. Insulin in the supernatant was then measured as described previously (8) using a rat-insulin ELISA kit (Crystal Chem Inc.). Insulin release was expressed as percentage of insulin content. In the remaining 15 islets, islet DNA was measured using the CyQUANT cell proliferation assay kit (Molecular Probes Inc.).

UCP2 gene expression in pancreatic islets in low and high glucose

UCP2 mRNA was analyzed using quantitative PCR. RNA was extracted from cultured islets using the RNeasy Mini Kit (QIAGEN Inc., Valencia, California, USA). Islet RNA was reverse transcribed with Superscript II
(Invitrogen Corp., Carlsbad, California, USA) and amplified using Stratagene Brilliant QPCR Core reactions (Stratagene, La Jolla, California, USA) with TaqMan probes and primers (Biosearch Technologies Inc., Novato, California, USA). Primer and probe sequences were as follows: sense, 5'-GCATTGCAGATCTCATCACTTTCC; antisense, $5^{\prime}$-AGCCCTTGACTCTCCCCTTG; probe sequence, $5^{\prime}$ FAM-TCTGGATACCGCCAAGGTCCGGCT-TAMRA. Relative expression of UCP2 mRNA was determined using standard curves based on islet cDNA, and samples were adjusted for total RNA content by $18 \mathrm{~S}$ ribosomal RNA quantative PCR (Applied Biosystems, Foster City, California, USA). Quantitative PCR was performed on an Mx4000 instrument (Stratagene). Assays were linear over five orders of magnitude.

Measurement of mitochondrial superoxide production in dispersed islet cells isolated from WT and UCP2 KO mice at low and high glucose

Dispersed islet cells were prepared for imaging as described above from WT or UCP2-deficient islets that had been incubated at low $(5.5 \mathrm{mM})$ or high $(25$ $\mathrm{mM})$ glucose for 72 hours. Islets from $o b / o b$ mice were incubated overnight only in RPMI $1640(11 \mathrm{mM}$ glucose, supplemented with $7.5 \%$ FCS and $1 \%$ penicillin-streptomycin).

To measure superoxide production in intact cells, ethidium imaging and analysis were carried out essentially as described previously $(17,26)$ and below. Coverslips were placed on the stage of a Zeiss Axiovert 200M inverted microscope (Carl Zeiss MicroImaging Inc., Thornwood, New York, USA) equipped with a Polychrome IV monochromator (TILL Photonics, Gräfelfing, Germany) and with a Roper Scientific CoolSnap HQ 12-bit cooled charge-coupled device (CCD) camera (Roper Scientific Inc., Trenton, New Jersey, USA). Cells were excited at $480 \mathrm{~nm}$, and ethidium emitted-light was collected using a Cy3 filterset (Chroma, Brattleboro, Vermont, USA). Sequential digital images were acquired every 30 seconds, with exposure times of 1,500 milliseconds, using a $\times 20,0.75$ numerical-aperture Fluar objective (Carl Zeiss Inc.). Images were acquired, stored, and analyzed using MetaMorph software (Universal Imaging Corp., Downingtown, Pennsylvania, USA). After a base line was acquired for $5 \mathrm{~min}$ utes, medium was replaced between two acquisition points with RPMI 1640 containing $1 \mu \mathrm{g} / \mathrm{ml}$ hydroethidine (Molecular Probes Inc.) (17). After 2 minutes, linear increases in fluorescence were observed. After 10 minutes, the medium was replaced with medium containing hydroethidine and FCCP $(2 \mu \mathrm{M})$ to collapse mitochondrial membrane potential and, consequently, obliterate mitochondrial superoxide.

For analysis of the images, five to eight cells per coverslip were identified as regions of interest, and adjacent fields not containing any cells were taken as background. The average fluorescence intensity of all regions of interest and of the background was determined for each frame. Fluorescence intensities were 
normalized to the initial value for comparative purposes. Average relative fluorescence for both the superoxide signal and the background was plotted against time, and slopes were calculated for the tracings after addition of the hydroethidine and hydroethidine plus FCCP. The fluorescent signal indicative of mitochondrial superoxide production was defined as that which was sensitive to addition of the mitochondrial uncoupler FCCP. To confirm that the measurements were specific for superoxide, and that the FCCP-sensitive signal originated from mitochondria, we used overexpression of MnSOD, the mitochondrial isoform of superoxide dismutase, as a control (data not shown). As expected, overexpression of MnSOD completely abrogated the FCCP-sensitive signal, confirming that it represented mitochondrial superoxide.

\section{Islet incubation in chronic hyperglycemia}

Isolation of islets and incubation conditions. Male mice, aged 12-20 weeks, were used for islet studies. (ob/ob islet studies are described in a separate section below.) Islets from eight mice of each genotype were pooled for insulin-release studies. After being isolated as described previously (8), islets were incubated overnight in RPMI 1640 (11 mM glucose, $7.5 \%$ FCS, $1 \%$ penicillin-streptomycin). A subset of islets was transduced with adenovirus driving expression of MnSOD and GPX1 $(100,000 \mathrm{PFUs} /$ islet $)$ as described previously $(21,22)$.

On the next day, all islets were transferred to RPMI 1640 (5.5 or $25 \mathrm{mM}$ glucose, $7.5 \%$ FCS) and incubated for 72 hours at $37^{\circ} \mathrm{C}$. After chronic incubation, all islets were washed three times with DMEM. Medium-sized islets (of the same size) were used for determination of insulin release, insulin content, and DNA content.

Insulin release. For each of the different conditions (chronic incubation at 5.5 and $25 \mathrm{mM}$ glucose, with or without overexpression of either MnSOD or GPX1), three islets were transferred to an Eppendorf tube containing $1 \mathrm{ml}$ of fresh DMEM $(5.5,12.5$, and $25 \mathrm{mM}$ glucose plus $0.1 \%$ gelatin) and incubated at $37^{\circ} \mathrm{C}$ for 1 hour. Five to eight parallel repeats were performed for each condition. After an hour, an aliquot of medium was frozen until insulin was measured as described previously (8).

Determination of insulin content. In a separate subset of islets, 15 islets for each condition (chronic incubation at 5.5 and $25 \mathrm{mM}$ glucose, with or without overexpression of either MnSOD or GPX1) were used for determination of insulin content, and at least five repeats were performed. Islets were homogenized using lysate buffer as described previously (25) and above, and total protein extract was immediately frozen until insulin measurement.

Determination of DNA content. In a separate set of islets, 15 islets for each condition (chronic incubation at 5.5 and $25 \mathrm{mM}$ glucose, with or without overexpression of either MnSOD or GPX1) were used for determination of DNA content as described previously (8). Also, islets previously used for insulin-release studies were used for determination of DNA content. Altogether, three to five repeats were performed for each condition (chronic incubation at 5.5 and $25 \mathrm{mM}$ glucose, with or without overexpression of either MnSOD or GPX1).

Calculation of insulin release as percent of insulin content. For each condition (chronic incubation at 5.5 and 25 $\mathrm{mM}$ glucose, with or without overexpression of either MnSOD or GPX1), the average data from the insulinrelease studies were divided by individual values of insulin content, yielding at least five values of insulin release per content per condition. These values were then averaged, and altogether the experiment was repeated on three different days. Data presented are averages of the mean results of three independent experiments \pm SEM.

\section{Insulin-secretion studies in $o b / o b$ islets}

$o b / o b$ mice lacking UCP2 were created as described previously (8). Briefly, $u c p 2^{+/-}$mice (on the mixed C57BL/6;J129 background) and $o b /+$ mice (C57BL/6 background, purchased from The Jackson Laboratory, Bar Harbor, Maine, USA) were crossed to generate double heterozygotes. These double heterozygotes were then crossed to generate $o b / o b$ and $o b / o b / \mathrm{UCP} 2$ KO mice. Therefore, these mice are on the mixed C57BL/6;J129 background. Between 10 and 20 weeks, these mice have impaired GSIS in vivo (8), consistent with other reports in the $o b / o b$ model $(27,28)$. Male mice, aged 16-20 weeks, were used for islet studies. The glucose levels of $o b / o b$ mice were between 250 and $350 \mathrm{mg} / \mathrm{dl}$, and those of $o b / o b / \mathrm{UCP} 2 \mathrm{KO}$ mice ranged from 195 to $235 \mathrm{mg} / \mathrm{dl}$. For each genotype, islets from three mice were pooled for insulin-release studies. After being isolated as described previously (8), islets were incubated overnight in RPMI $1640(11 \mathrm{mM}$ glucose, $7.5 \%$ FCS, $1 \%$ penicillin-streptomycin). A subset of islets was transfected with adenovirus driving expression of MnSOD (100,000 PFUs per islet) as described above. On the next day, islets were washed three times with DMEM. Medium-sized islets (of the same size) were used for determination of insulin release (eight to ten measurements per condition), insulin content (at least five measurements per condition), and DNA content (at least five measurements per condition). Insulin secretion was then expressed as percentage of content, whereby average data from the insulin-release studies were divided by individual values of insulin content, yielding at least five values of insulin release per insulin content. Data presented are average results from one representative experiment.

\section{Results}

Superoxide activates proton leak in mitochondria that express UCP2. It has previously been shown that exogenously added superoxide activates proton leak in isolated mitochondria expressing UCP2 (6). However, recently it was reported that this finding could not be reproduced (29). In order to resolve these conflicting findings, mitochondria were isolated from kidney and 


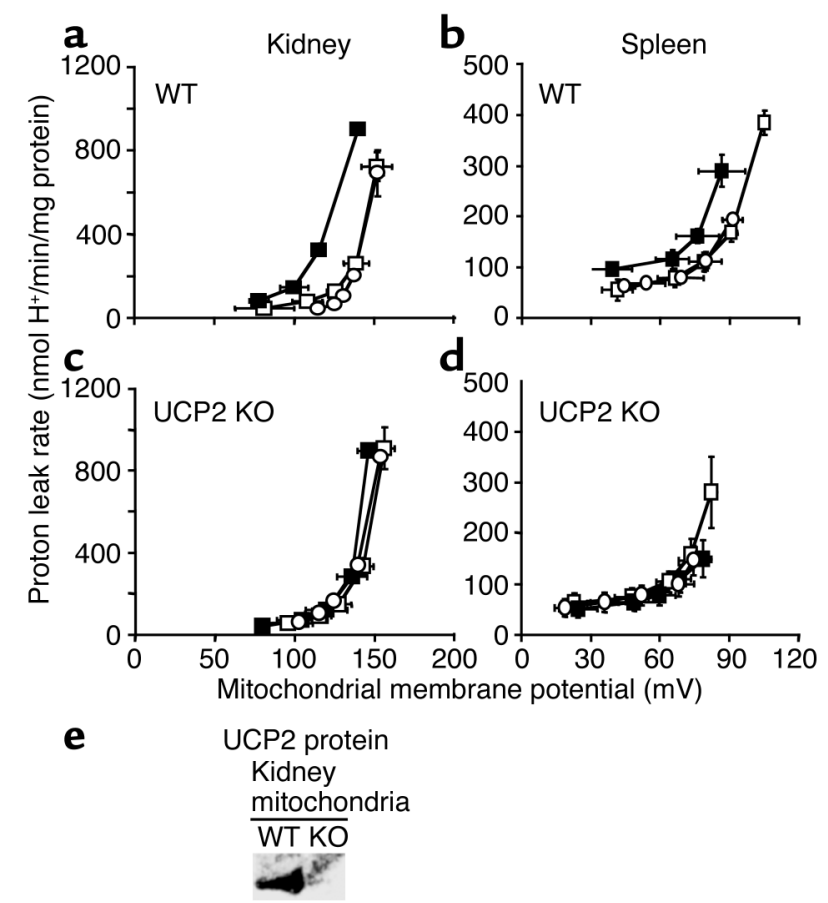

Figure 1

Effects of superoxide on proton conductance of kidney ( $\mathbf{a}$ and $\mathbf{c}$ ) and spleen ( $\mathbf{b}$ and $\mathbf{d}$ ) mitochondria isolated from WT ( $\mathbf{a}$ and $\mathbf{b}$ ) and UCP2deficient ( $\mathbf{c}$ and $\mathbf{d}$ ) mice. Proton leak titration was performed with or without addition of a superoxide-generating system (xanthine plus xanthine oxidase), essentially as described previously (30) and in Methods. Graphs show the rate of proton leak as a function of its driving force, mitochondrial membrane potential. Open squares, control; filled squares, xanthine $(50 \mu \mathrm{M})$ plus xanthine oxidase $(0.2 \mathrm{mU} / 3.5 \mathrm{ml}$ for kidney mitochondria, $0.1 \mathrm{mU} / 3.5 \mathrm{ml}$ for spleen mitochondria); open circles, xanthine/xanthine oxidase plus $500 \mu \mathrm{M}$ GDP. Western blot analysis confirmed that UCP2 protein was present in kidney (e) and spleen mitochondria (8) of WT mice, and that UCP2 protein was absent in mitochondria from UCP2 KO mice. Proton leak data are means \pm SEM of three independent experiments.

spleen of WT and UCP2-deficient mice, and proton leak was measured in the presence or absence of exogenous superoxide (6). In WT mitochondria, superoxide activated proton leak (Figure 1, a and b). Addition of GDP, a known inhibitor of UCP function, completely abolished superoxide-induced proton leak. In mitochondria lacking UCP2, addition of superoxide had no effect on proton leak (Figure 1, $c$ and d). These results confirm the findings of Echtay et al. $(6,30)$, that exogenously added superoxide increases proton leak in mitochondria isolated from UCP2-expressing tissues, and that this effect can be inhibited by GDP. In addition, the present study extends the previous findings by demonstrating that superoxide-induced proton leak in kidney and spleen mitochondria requires the presence of UCP2. However, unknown from these studies is whether endogenously generated levels of superoxide control UCP2-mediated proton leak and whether this has consequences for cellular bioenergetics and function.
Endogenously generated superoxide activates UCP2dependent proton leak in intact cells. We next investigated whether endogenously generated superoxide regulates UCP2-mediated proton leak in intact cells. Proton leak was assessed in thymocytes, a system ideally suited for measuring proton leak in intact cells $(18,31)$. Thymocytes were isolated from WT and UCP2-deficient mice, and proton leak was measured (7) with or without the addition of MnTBAP. MnTBAP is a cell-permeant superoxide dismutase mimetic (32) that catalyzes the conversion of superoxide to $\mathrm{H}_{2} \mathrm{O}_{2}$ and, to a much lesser extent, of $\mathrm{H}_{2} \mathrm{O}_{2}$ to water. Using UCP2 gene $\mathrm{KO}$ mice, we have previously demonstrated that UCP2 catalyzes approximately $50 \%$ of all mitochondrial proton leak in thymocytes (7). In the present study, addition of MnTBAP $(30 \mu \mathrm{M})$ to WT thymocytes caused a large reduction in proton leak (Figure 2a). This reduction was similar in magnitude to that caused by UCP2 deficiency (7) (WT control vs. KO control in Figure 2, a vs. b. Strikingly, the ability of MnTBAP to decrease proton leak was completely absent in UCP2-deficient thymocytes (Figure $2 \mathrm{~b}$ ), indicating that MnTBAP specifically inhibits proton leak mediated by UCP2 (note that thymocytes, like pancreatic $\beta$ cells, express UCP2 but not UCP1 or UCP3). These findings demonstrate that endogenous levels of ROS, most likely superoxide, activate UCP2-mediated proton leak. This observation represents, to our knowledge, the first demonstration of a physiologically relevant UCP2 regulator functioning in intact cells.

Effects of superoxide-induced, UCP2-dependent proton leak on cellular energy metabolism. It was previously reported that UCP2 expression controls ATP levels in cells (7). Consequently, superoxide-mediated activation of UCP2 should affect cellular energy metabolism. Thus, we next assessed the effects of superoxide-mediated proton leak on ATP production in cells. In agreement with an inhibitory effect on UCP2-mediated proton leak, addition of MnTBAP to WT thymocytes increased mitochondrial membrane potential (Figure 2c) and total ATP levels (Figure 2d). MnTBAP had no effect on total cellular oxygen consumption (Figure 2e) indicating, as had previously been reported (7), that UCP2mediated proton leak exerts greater control over ATP production than over substrate oxidation. MnTBAP had no effect on mitochondrial membrane potential or ATP levels in UCP2-deficient thymocytes (Figures 2, $c$ and d), indicating that superoxide-mediated regulation of these parameters requires the presence of UCP2. In conclusion, endogenous superoxide specifically activates UCP2-dependent proton leak. Moreover, UCP2dependent proton leak controls ATP production.

Operation of the superoxide-UCP2 pathway in pancreatic $\beta$ cells: effects on insulin secretion. Having established the importance of endogenously generated superoxide in controlling UCP2-mediated proton leak and ATP production in thymocytes, we then assessed the relevance of this pathway in pancreatic $\beta$ cells. Using real-time imaging (20), we investigated whether MnTBAP 

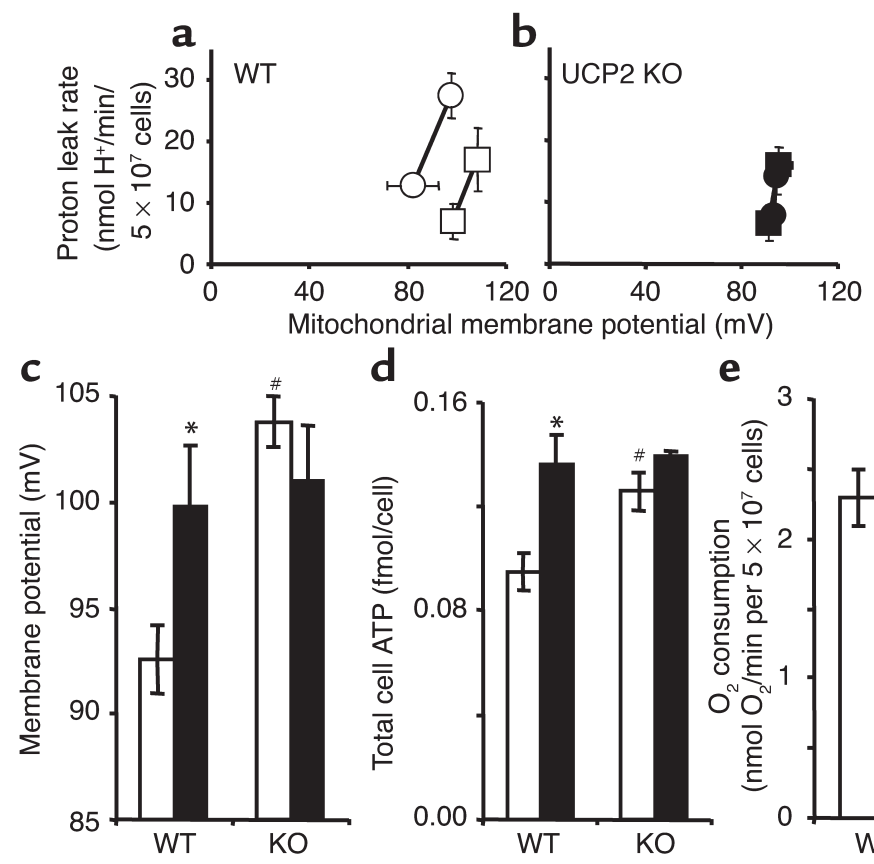

e

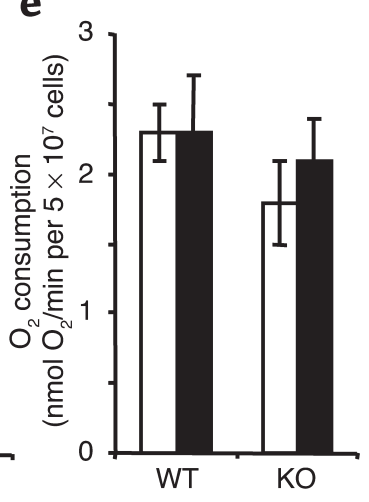

\section{Figure 2}

Effect of MnTBAP on proton leak, mitochondrial membrane potential, ATP, and oxygen consumption in intact thymocytes. ( $\mathbf{a}$ and $\mathbf{b}$ ) Proton leak in thymocytes. Thymocytes were incubated with oligomycin to block protons from re-entering the mitochondrial matrix via ATP synthase (top right points of each line). A submaximal concentration $(80 \mathrm{nM})$ of the electron-transport chain inhibitor myxothiazol was added to reduce mitochondrial membrane potential to the resting-cell level (bottom left points in each line). Analyses were performed in thymocytes isolated from WT (a) and UCP2-deficient mice (b). Circles, control; squares, proton leak in the presence of $\operatorname{MnTBAP}(30 \mu \mathrm{M})$. Results are expressed as means $\pm \operatorname{SEM}(n=4-6)$. (c-e) Mitochondrial membrane potential, total cell ATP, and oxygen consumption were measured in resting thymocytes (no inhibitors added). White bars, control; black bars, $30 \mu \mathrm{M}$ MnTBAP added. Cells were isolated from WT (left set of bars in each panel) and UCP2-deficient mice (right set of bars in each panel). Results are expressed as means \pm SEM $(n=3-7) .{ }^{*} P<0.05$, treated vs. untreated control; ${ }^{\#} P<0.05, \mathrm{UCP} 2$-deficient control vs. WT control. induced changes in mitochondrial membrane potential in dispersed islet cells, as measured by the mitochondrial membrane potential-sensitive fluorescent dye TMRM (Figure 3 , $a$ and $b$ ). Addition of MnTBAP to $\beta$ cells isolated from WT animals induced a rapid increase in mitochondrial TMRM fluorescence over time (compare WT, MnTBAP, with WT, no addition). Note that the increase in mitochondrial membrane potential was seen as early as $5 \mathrm{~min}$ utes after MnTBAP addition. In contrast, addition of MnTBAP to $\beta$ cells deficient in UCP2 had no effect on mitochondrial TMRM fluorescence (compare UCP2 KO, MnTBAP, with WT, no addition). Thus, addition of MnTBAP induced a pronounced increase in mitochondrial membrane potential over time in $\beta$ cells, and this effect required the presence of UCP2.

Because the TMRM method does not allow one to quantitate changes in membrane potential, we also estimated mitochondrial membrane potential using $\left[{ }^{3} \mathrm{H}\right] \mathrm{TPMP}^{+}(19)$ in intact islets isolated from WT and UCP2-deficient mice. Since MnTBAP may not be entirely specific for superoxide, we also used adenoviral overexpression of MnSOD (21), which specifically dismutates superoxide to $\mathrm{H}_{2} \mathrm{O}_{2}$. To assess any possible role of $\mathrm{H}_{2} \mathrm{O}_{2}$, we also employed adenoviral overexpression of GPX1 (16, 22), which converts $\mathrm{H}_{2} \mathrm{O}_{2}$ to water. Note that MnSOD is targeted to mitochondria, and GPX1 to both cytosol and mitochondria (22). Addition of MnTBAP and overexpression of MnSOD significantly increased mitochondrial membrane potential in WT islets, whereas GPX1 had no effect (Figure 3c). The lack of effect of GPX1 is noteworthy as it reduced total ROS levels (as assessed by CM$\mathrm{H}_{2}$ DCFDA) by $50 \%$ (data not shown). In contrast, neither MnTBAP nor MnSOD showed any effect on mitochondrial membrane potential in islets from UCP2-deficient mice. Consistent with the effects on mitochondrial membrane potential, MnTBAP and overexpression of MnSOD significantly increased ATP content in WT islets but had no effect in UCP2-deficient islets (Figure $3 \mathrm{~d}$ ). These studies strongly suggest that endogenously generated superoxide activates UCP2-mediated proton leak in pancreatic $\beta$ cells and show that this activation has important negative effects on ATP levels, a major coupling signal between glucose sensing and insulin secretion. In addition, the lack of effect of GPX1 overexpression on mitochondrial membrane potential demonstrates that $\mathrm{H}_{2} \mathrm{O}_{2}$, or some ROS downstream of $\mathrm{H}_{2} \mathrm{O}_{2}$, may not be responsible for the regulation of UCP2.

Given that endogenous superoxide activates UCP2 in islets, and that UCP2 negatively regulates insulin secretion $(8,9)$, removal of endogenous superoxide should increase insulin secretion in islets in a UCP2-dependent manner. We therefore assessed GSIS in islets treated with MnTBAP, or infected with adenovirus driving overexpression of MnSOD or GPX1 (Figure 3e). MnTBAP and MnSOD increased insulin secretion in WT islets, whereas reduction of $\mathrm{H}_{2} \mathrm{O}_{2}$ levels by overexpression of GPX1 had no effect (Figure 3e, first set of bars).

Co-overexpression of MnSOD and GPX1 increased insulin secretion by the same amount as overexpression of $\mathrm{MnSOD}$ alone, indicating that a potential increase in $\mathrm{H}_{2} \mathrm{O}_{2}$, secondary to increased MnSOD activity, was not the cause of the observed change in insulin secretion. In contrast, neither MnTBAP nor overexpression of MnSOD or GPX1 had any effect on insulin secretion in UCP2-deficient islets (Figure 3e, second set of bars). Of interest, the effects of MnTBAP were dose dependent in the WT islets (Figure 3e, inset). 

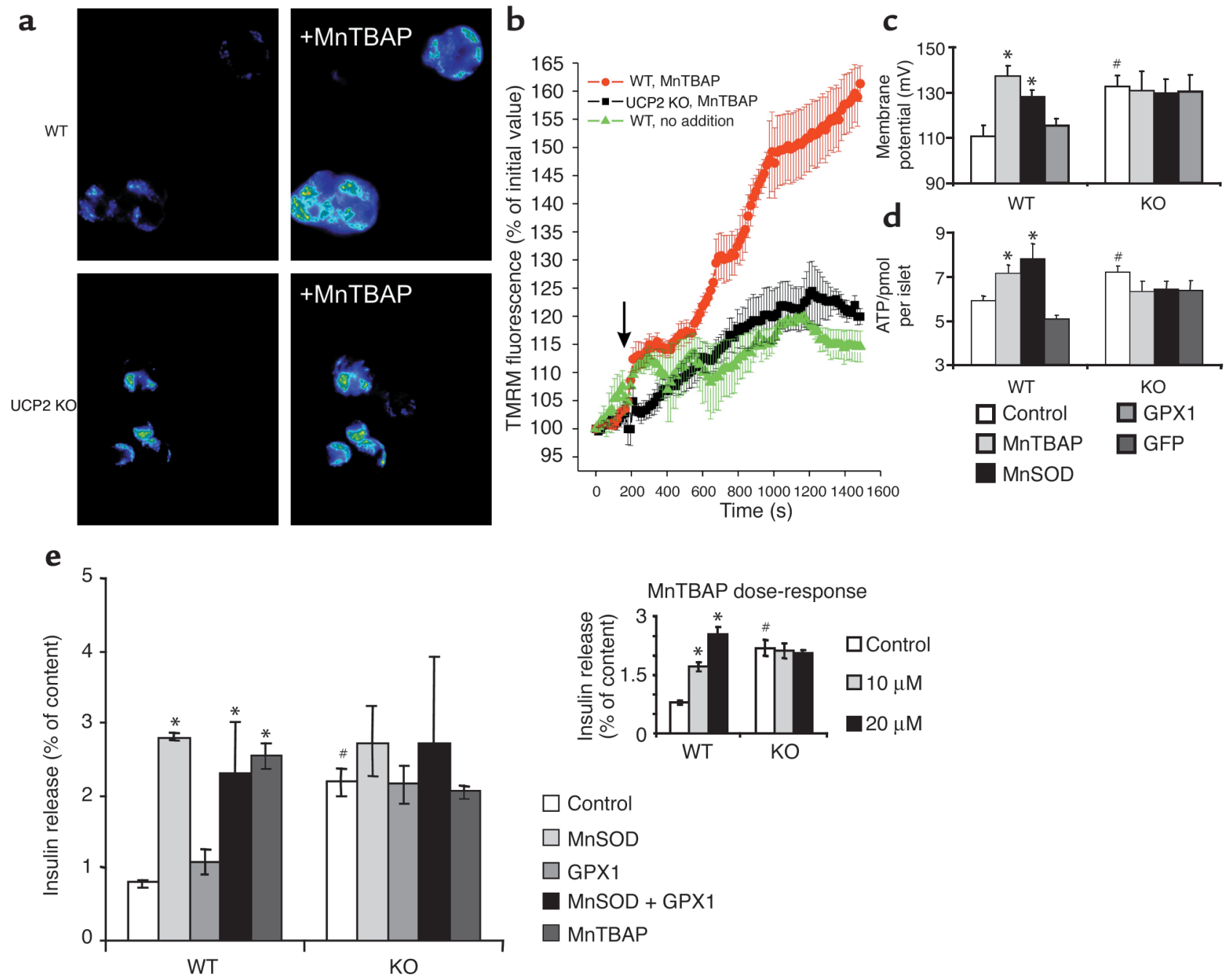

Figure 3

Role of superoxide in dispersed islet cells and pancreatic islets in regulating mitochondrial membrane potential (a-c), ATP levels (d), and insulin secretion (e). (a) Pseudocolor-coded representative images ofTMRM fluorescence intensity in WT and UCP2-deficient dispersed islet cells at the beginning (left) and at the end of the acquisition sequence (right, with $25 \mu \mathrm{M}$ MnTBAP). After 4 minutes, cells were exposed to $25 \mu \mathrm{M}$ MnTBAP. (b) Quantitation of the TMRM fluorescence changes over mitochondrial regions. Where indicated by the arrow, $25 \mu \mathrm{M}$ MnTBAP was added, except for control (WT, no addition). Results are means $\pm \operatorname{SD}(n=4)$. (c-e) Quantitation of mitochondrial membrane potential, total ATP, and insulin secretion in islets. Islets were isolated from WT and UCP2 KO mice. Islets were treated with MnTBAP, or adenovirus driving the overexpression of MnSOD or GPX1. In some cases, islets were treated with adenovirus driving the expression of GFP as a control for the MnSOD adenovirus studies. In e, insulin content of islets was as follows: WT, $248 \pm 11 \mathrm{ng}$ per islet; UCP2 KO, $251 \pm 16 \mathrm{ng}$ per islet. These values were used to express insulin secretion as percentage of insulin content. For c-e, results are means \pm SEM. (c) $n=3-5$; (d) $n=8-20$ ( $n=3$ for GFP control); (e) $n=3-5$. ${ }^{*} P<0.05$, treated vs. untreated control; ${ }^{*} P<0.05$, UCP2-deficient control vs. WT control.

MnTBAP had no effect in islets deficient in UCP2. Thus, the effects of removing superoxide on insulin secretion require the presence of UCP2. Furthermore, these results suggest that superoxide has regulatory capacity with respect to UCP2 activity. Taken together, these studies show that, under physiological conditions, superoxide negatively regulates insulin secretion by activating UCP2, thus decreasing mitochondrial membrane potential and, consequently, ATP, which is a major signal for GSIS.

Effects of hyperglycemia and obesity on superoxide and UCP2 levels in islets. Hyperglycemia increases ROS levels in many cell types $(10,12-15)$, including $\beta$ cells (16). Of interest, UCP2 levels are upregulated by hyperglycemia in vitro $(10,11)$, and in islets of hyperglycemic animals such as $o b / o b$ mice (8) and partially pancreatectomized rats (11). Thus, we hypothesized that a superoxideUCP2 pathway would contribute importantly to hyperglycemia-induced impairment in GSIS, and thus the development of type 2 diabetes.

To confirm that UCP2 levels in islets are upregulated by hyperglycemia, we first measured UCP2 mRNA levels in islets exposed to $25 \mathrm{mM}$ glucose for 72 hours (Figure 4a). Hyperglycemia increased UCP2 mRNA about threefold. Adenoviral overexpression of MnSOD did not lead to a decrease in hyperglycemia-induced 
a

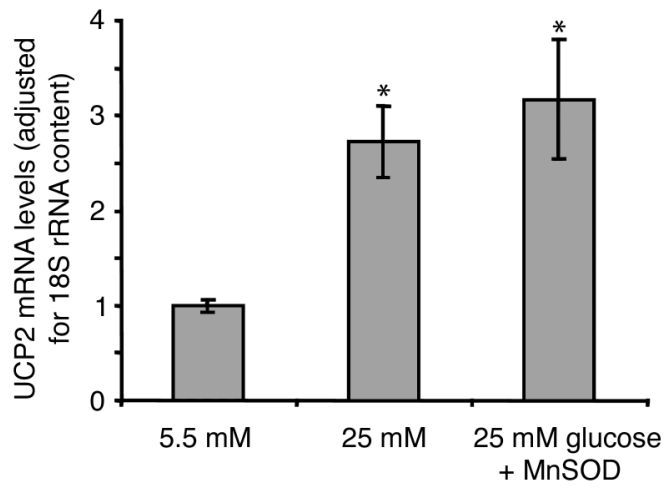

b

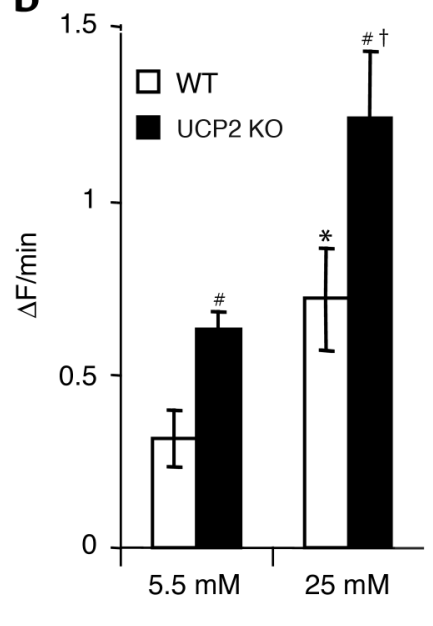

c

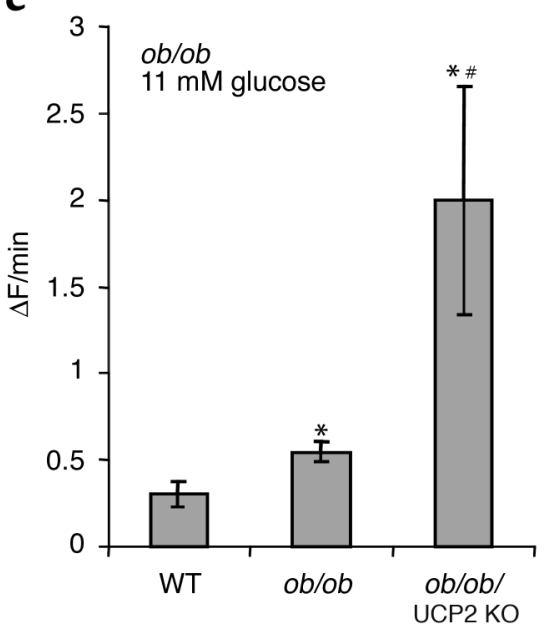

Figure 4

UCP2 expression and mitochondrial superoxide production in islets and dispersed islet cells. (a) UCP2 mRNA expression levels in islets cultured for 3 days at low $(5.5 \mathrm{mM})$ and high glucose $(25 \mathrm{mM})$. Expression levels are expressed as relative to the low-glucose (5.5 mM) incubation group. Astrisks indicate $P<0.05$, high glucose vs. low glucose control. (b) Mitochondrial superoxide production in low and high glucose in dispersed islet cells from WT and UCP2 KO mice, as measured by time-dependent conversion of the superoxide-sensitive dye hydroethidine (17). Results are means $\pm \operatorname{SEM}(n=4-7)$. ${ }^{*} P<0.05$, WT $(25 \mathrm{mM}$ glucose $)$ vs. WT $(5.5 \mathrm{mM}$ glucose); $P<0.05$, UCP2-deficient vs. WT at 5.5 $\mathrm{mM}$ glucose; $\uparrow P<0.05$, UCP2-deficient cells ( $25 \mathrm{mM}$ glucose) vs. UCP2-deficient cells ( 5.5 mM glucose). (c) Mitochondrial superoxide production in dispersed islet cells from WT, ob/ob, and $o b / o b / \mathrm{UCP} 2 \mathrm{KO}$ mice, as measured by conversion of the superoxide-sensitive dye hydroethidine. $\Delta \mathrm{F} / \mathrm{min}$ denotes the change in relative fluorescence intensity $(\mathrm{F})$ as a function of time. Results are means $\pm \mathrm{SEM}(n=3)$. ${ }^{*} P<0.05, o b / o b$ or ob/ob/UCP2 KO vs. WT; ${ }^{*} P<0.05, o b / o b / U C P 2 \mathrm{KO}$ vs. ob/ob.

UCP2 overexpression, indicating that the effect of hyperglycemia on UCP2 expression was independent of superoxide levels in islets.

To specifically test whether hyperglycemia also increases superoxide levels in islets, we first measured mitochondrial superoxide levels in dispersed islet cells from WT and UCP2 KO mice following chronic hyperglycemia (72 hours). Superoxide was detected in dispersed pancreatic islet cells using hydroethidine (17). Hyperglycemia approximately doubled mitochondrial superoxide production in both WT and UCP2 KO islet cells (Figure 4b) compared with low-glucose conditions $(5.5 \mathrm{mM})$. Of note, islet cells lacking UCP2 had roughly doubled mitochondrial superoxide levels compared with WT cells. The stimulatory effects of hyperglycemia and UCP2 deficiency were additive. These results demonstrate that hyperglycemia increases mitochondrial superoxide production. They also demonstrate, as has previously been shown in other cell types, that UCP homologs UCP2 (33-35) and UCP3 (36) decrease mitochondrial superoxide production.

To see whether mitochondrial superoxide levels are increased in islet cells of obese, diabetic mice, we also measured mitochondrial superoxide in freshly isolated islet cells from hyperglycemic $o b / o b$ mice. Islet cells were incubated at $11 \mathrm{mM}$ glucose to mimic the elevated blood glucose levels in $o b / o b$ mice. Islet cells from $o b / o b$ mice had approximately double the mitochondrial superoxide levels that the WT controls had (Figure 4c). This is consistent with a recent report showing that islets from obese Zucker diabetic fatty (ZDF) rats, which lack functional leptin receptors, have elevated superoxide production (17). Islet cells isolated from $o b / o b$ mice lacking UCP2 had even higher superoxide levels, consistent with UCP2 being a negative regulator of superoxide production. The greater-than-additive effect of UCP2 gene KO and obesity with hyperglycemia on superoxide production in $o b / o b / \mathrm{UCP} 2-$ deficient islets (Figure 4c, third bar) strongly suggests that the marked upregulation of UCP2 observed in $o b / o b$ islets (8) plays an important role in restraining mitochondrial superoxide production.

The role of superoxide and UCP2 in hyperglycemia- and obesity-induced $\beta$ cell dysfunction. To establish whether increased superoxide in combination with induction of UCP2 in hyperglycemia contributes to hyperglycemiainduced impairment of GSIS, we incubated WT and UCP2-deficient islets with 5.5 and $25 \mathrm{mM}$ glucose for 72 hours and then assessed GSIS. As expected, WT islets chronically incubated at low glucose released increasing amounts of insulin in response to increasing concentrations of glucose (Figure 5a, first set of bars). Following chronic hyperglycemia, islets increased basal insulin release from $0.19 \%$ to $1.7 \%$ but were completely unresponsive to glucose stimulation (Figure 5a, second set of bars). These data are consistent with other reports showing that chronic hyperglycemia increases basal insulin secretion and, at the same time, causes complete loss of glucose responsiveness $(37,38)$. To assess the role of superoxide in causing hyperglycemiainduced loss of glucose responsiveness, we overexpressed MnSOD in islets during the chronic hyper- 


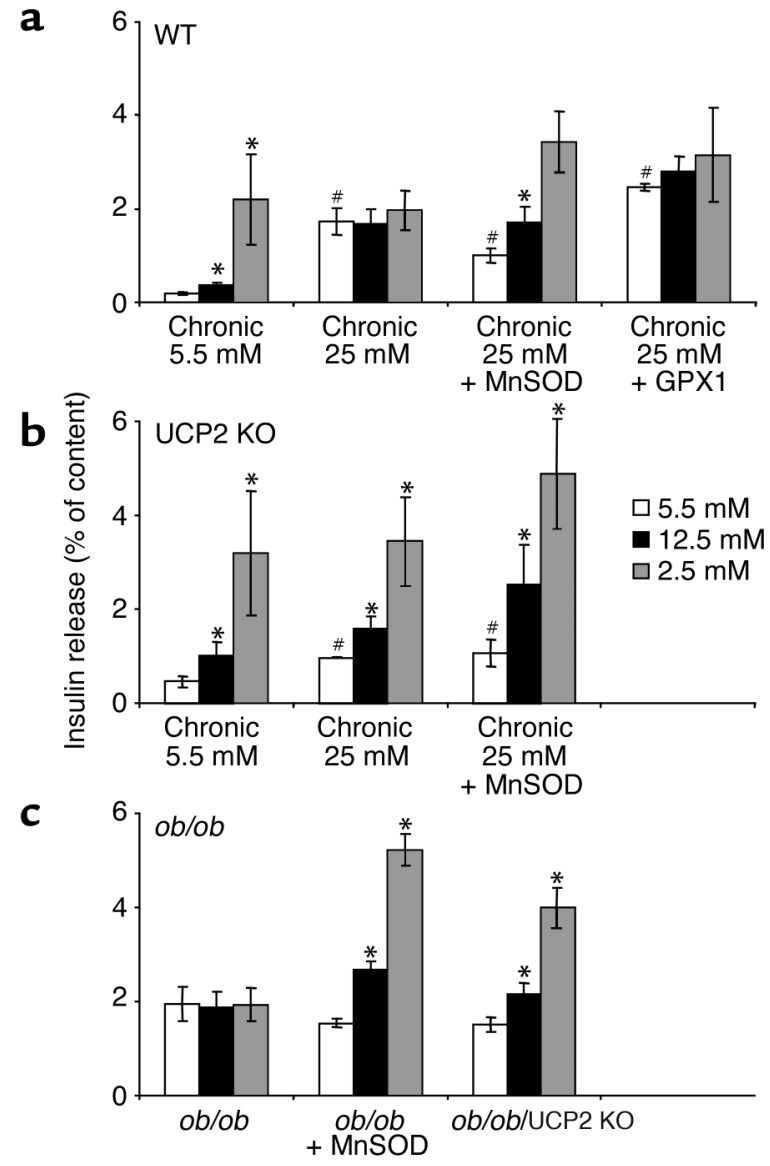

Figure 5

Effects of hyperglycemia and obesity on $\beta$ cell dysfunction in WT and UCP2-deficient islets, with or without overexpression of MnSOD and GPX1. Pancreatic islets were isolated from WT (a) or UCP2 KO mice (b) and subjected to chronic incubations at low and high glucose. In a separate experiment, islets were isolated from $o b / o b$ mice (c). Adenovirus-driven overexpression of MnSOD and GPX1 was used where indicated. Islets were incubated for a total of 72 hours and washed, and then insulin-secretion studies were performed using three different concentrations of glucose $(5.5,12.5$, and $25 \mathrm{mM})$. Insulin- and DNA-content data are reported for reference in Table 1. Results are means \pm SEM of three independent experiments ( $\mathbf{a}$ and $\mathbf{b}$ ) or five repeats of one representative experiment $(\mathbf{c}) .{ }^{*} P<0.05$, higher glucose vs. lowest glucose condition in each group; ${ }^{\#} P<0.05$, basal secretion (chronic hyperglycemia) vs. basal secretion (5.5 mM glucose).

glycemic incubations. Overexpression of MnSOD prevented the hyperglycemia-induced block in GSIS (Figure $5 \mathrm{a}$, third set of bars). This beneficial effect of MnSOD was not caused by prevention of hyperglycemia-induced increases in UCP2 mRNA levels, since UCP2 mRNA levels were unaffected by overexpression of MnSOD (Figure 4a). To assess the possibility that hydrogen peroxide also contributes to the specific impairment of GSIS, we overexpressed GPX1 to remove hydrogen peroxide $(16,22)$. GPX1 overexpression did not prevent hyperglycemia-induced loss of GSIS in WT islets (Figure 5a, last set of bars), indicating that superoxide, not $\mathrm{H}_{2} \mathrm{O}_{2}$, is the relevant ROS that causes hyperglycemia-induced loss of glucose sensing.
The data described above demonstrate that superoxide causes hyperglycemia-induced impairment of GSIS. To see whether this effect of superoxide requires the presence of UCP2, islets were isolated from UCP2 $\mathrm{KO}$ mice and then incubated in chronic hyperglycemia. Following chronic incubation in low glucose $(5.5 \mathrm{mM})$, UCP2 KO islets, like WT islets, released increasing amounts of insulin in response to increasing concentrations of glucose (Figure $5 b$, first set of bars). Consistent with the inhibitory effect of UCP2 on insulin secretion, levels of insulin secretion were higher than those observed in WT islets (Figure 5 a, first set of bars) at all three concentrations of glucose. However, unlike WT islets, islets from UCP2 KO mice, when incubated at $25 \mathrm{mM}$ glucose, retained glucose responsiveness (Figure $5 \mathrm{~b}$, second set of bars). Their pattern of response was similar to that observed in WT islets overexpressing MnSOD (Figure $5 \mathrm{a}$, third set of bars). Islets lacking UCP2, when exposed to chronic hyperglycemia, similar to WT islets overexpressing MnSOD, still retain elevated basal insulin secretion. Therefore, elevated basal insulin secretion in hyperglycemia, unlike glucose responsiveness, is independent of the hyperglycemiainduced increase in UCP2 and superoxide levels. Importantly, overexpression of MnSOD in UCP2 KO islets had no additional beneficial effect on GSIS (Figure 5b, last set of bars), indicating that superoxide-mediated loss of glucose responsiveness is caused by activation of UCP2.

To see whether this model of hyperglycemiainduced $\beta$ cell dysfunction and impairment of GSIS is relevant to the pathophysiology of obesity-induced type 2 diabetes, we studied insulin secretion in islets from $o b / o b$ mice and from $o b / o b$ mice lacking UCP2. In these islets, both superoxide levels (Figure 4c) and UCP2 expression levels (8) are increased compared with WT islets. Islets from $o b / o b$ mice showed elevated basal insulin secretion and loss of glucose responsiveness compared with WT islets (Figure 5c, first set of bars, vs. Figure $5 \mathrm{a}$, first set of bars), similar to what was observed in WT islets following chronic hyperglycemia (Figure 5a, second set of bars). Overexpression of MnSOD restored glucose sensing in $o b / o b$ islets, indicating that elevated superoxide levels cause loss of glucose responsiveness (Figure $5 \mathrm{c}$, second set of bars). Islets isolated from $o b / o b$ mice lacking UCP2 also had restored GSIS (Figure 5c, last set of bars), similar to $o b / o b$ islets overexpressing MnSOD, and also similar to WT islets overexpressing MnSOD (Figure 5a, third set of bars), or UCP2-deficient islets during exposure to hyperglycemia (Figure 5b, second set of bars). Of note, MnSOD overexpression in islets from $o b / o b$ mice lacking UCP2 did not improve glucose sensing above the level seen in islets lacking UCP2 alone (data not shown). Therefore, superoxide activation of UCP2 causes significant impairment of GSIS in $a b / o b$ islets, a rodent model of obesityinduced type 2 diabetes. 


\section{Table 1}

Insulin and DNA content of WT and UCP2-deficient islets incubated in chronic hyperglycemia, or islets isolated from $o b / o b$ mice

\begin{tabular}{|c|c|c|}
\hline \multicolumn{3}{|c|}{ Insulin content (ng insulin/islet) } \\
\hline \multicolumn{3}{|l|}{ WT } \\
\hline \multicolumn{3}{|l|}{ Glucose (mM) } \\
\hline 5.5 & 25 & $25+\mathrm{MnSOD}$ \\
\hline $273.5 \pm 20.8$ & $543.9 \pm 53.8$ & $292.9 \pm 22.9$ \\
\hline \multicolumn{3}{|l|}{ UCP2 KO } \\
\hline \multicolumn{3}{|l|}{ Glucose (mM) } \\
\hline 5.5 & 25 & $25+\mathrm{MnSOD}$ \\
\hline $319.4 \pm 37.2$ & $432.5 \pm 73.8$ & $232.2 \pm 27.1$ \\
\hline \multicolumn{3}{|l|}{$o b / a b$} \\
\hline$o b / o b$ & $o b / o b / \mathrm{KO}$ & $o b / o b / \mathrm{MnSOD}$ \\
\hline $7,308 \pm 1,500$ & $6,869 \pm 882$ & $6,179 \pm 380$ \\
\hline \multicolumn{3}{|l|}{ DNA (ng/islet) } \\
\hline \multicolumn{3}{|l|}{ WT } \\
\hline \multicolumn{3}{|l|}{ Glucose (mM) } \\
\hline 5.5 & 25 & $25+\mathrm{MnSOD}$ \\
\hline $5.5 \pm 2.3$ & $9.9 \pm 3.9$ & $6.4 \pm 0.4$ \\
\hline \multicolumn{3}{|l|}{ UCP2 KO } \\
\hline \multicolumn{3}{|l|}{ Glucose (mM) } \\
\hline 5.5 & 25 & $25+\mathrm{MnSOD}$ \\
\hline $5.7 \pm 0.8$ & $8.7 \pm 3.7$ & $5.0 \pm 0.8$ \\
\hline \multicolumn{3}{|l|}{$o b / o b$} \\
\hline$o b / o b$ & $o b / o b / \mathrm{KO}$ & $o b / o b / \mathrm{MnSOD}$ \\
\hline $57.3 \pm 13.6$ & $55.5 \pm 8.4$ & $79.3 \pm 14.2$ \\
\hline
\end{tabular}

The insulin-content data were used to calculate the insulin-secretion data (insulin secreted as percentage of content) presented in Figure 5, a-c. As can be seen from the table, a 72-hour incubation at $25 \mathrm{mM}$ glucose increased both DNA and insulin content in islets isolated from WT and UCP2-deficient mice, relative to the low-glucose control. However, insulin content relative to DNA content is unchanged following chronic hyperglycemia, consistent with a previous report showing that insulin content per cell of pancreatic $\beta$ cells cultured at high glucose for 3 days is unchanged (54).

\section{Discussion}

The present study demonstrates that endogenously produced superoxide activates UCP2-mediated proton leak in thymocytes and pancreatic $\beta$ cells. Removal of endogenous superoxide, or UCP2 (by means of gene knockout), causes decreased proton leak, increased mitochondrial membrane potential, and increased ATP levels. While the physiological importance of this superoxide-UCP2 pathway for T cell function is currently unknown, the present study demonstrates that this pathway plays an important role in negatively regulating GSIS.

Impaired secretion of insulin by pancreatic $\beta$ cells, together with resistance to insulin action, causes type 2 diabetes. A large body of work has established that chronic hyperglycemia leads to loss of GSIS $(1,3)$. However, the mechanism for this effect, which contributes importantly to the pathogenesis of type 2 diabetes, remains unclear. A role for hyperglycemia-induced ROS production in $\beta$ cell dysfunction has been suggested by multiple studies (16, 39-43); however, at present, the mechanisms responsible for ROS-mediated $\beta$ cell dysfunction, and their importance, are unclear.
Here, we demonstrate that hyperglycemia causes increased mitochondrial superoxide production, which in turn leads to activation of UCP2, and, consequently, impairment of GSIS. Interrupting the pathway of superoxide-mediated activation of UCP2 in islets prevents the loss of GSIS that normally results from chronic hyperglycemia, or extreme obesity (in $o b / o b$ mice). Thus, superoxide-mediated activation of UCP2 plays an important role in causing hyperglycemia- and obesity-induced loss of glucose responsiveness. While our studies focused on chronic hyperglycemia, it is formally possible that chronic hyperlipidemia, which is known to cause loss of GSIS in islets $(44,45)$, also affects insulin secretion through the superoxide-UCP2 pathway. In support of this hypothesis, it has been found that hyperlipidemia upregulates UCP2 expression levels in islets $(46,47)$, and that FFAs cause elevation of ROS levels in $\beta$ cells (45). Of note, a recent report suggests that UCP2-deficient islets maintain glucose responsiveness after long-term incubation with palmitic acid, whereas WT islets become unresponsive to glucose (44). However, a role for superoxide in this process has not yet been assessed. In conclusion, it is possible that hyperlipidemia, like hyperglycemia, causes superoxide-mediated activation of UCP2 and, consequently, loss of glucose sensing.

The $o b / o b$ mouse is a model of obesity-induced type 2 diabetes and is characterized by severe insulin resistance, hyperinsulinemia, hyperglycemia, and loss of GSIS $(27,48,49)$. UCP2 expression levels are upregulated in $o b / o b$ islets (8), and, as we show here, mitochondrial superoxide, which activates UCP2, is also elevated. It has also recently been shown that superoxide levels are increased in islets from obese ZDF rats (17). $o b / o b$ mice lacking UCP2 have restored firstphase insulin secretion, increased serum insulin levels, and greatly decreased blood glucose (8). In contrast, these mice do not have altered insulin sensitivity, indicating that the improvement of glucose homeostasis is due to improved $\beta$ cell function. In the present study, using isolated islets from $o b / o b$ and $o b / o b / \mathrm{UCP} 2$ KO mice, we show that deficiency of UCP2, or removal of mitochondrial superoxide, restored GSIS. Taken together, these data clearly demonstrate that interrupting the superoxide-UCP2 pathway improves impairment of GSIS in $o b / o b$ islets and strongly support the conclusion that this novel pathway could be relevant to the etiology of type 2 diabetes.

What is the physiological role of UCP 2 in the $\beta$ cell? It has been suggested that the purpose of UCP homologs, which are widely distributed and highly conserved, may be to reduce mitochondrial superoxide (and therefore ROS) production $(6,33,34,36)$. This is because they decrease mitochondrial membrane potential, which is known to reduce superoxide formation (50). Thus it is likely that a feedback loop exists in cells that express UCPs whereby abnormally increased superoxide levels induce UCP-dependent uncoupling, which, in turn, reduces mitochondrial membrane potential and thus 
superoxide generation. Indeed, several recent findings provide evidence to support this model. (a) Superoxide activates proton leak in a UCP-dependent manner not only in isolated mitochondria (6), but also, as we show here, at physiological levels in intact cells. (b) Superoxide levels are increased in skeletal muscle mitochondria from UCP3-deficient mice (36), as well as in macrophages (35) and (as we show here) dispersed islet cells of UCP2-deficient mice. (c) Mitochondria from mice that lack UCP3 show a tendency toward elevated levels of oxidative protein damage (51).

On the other hand, if UCP2 were critical in the protection of $\beta$ cells against ROS, one would expect severe consequences for $\beta$ cells lacking UCP2, especially in the long term, such as increased ROS-mediated cell damage and loss of $\beta$ cell mass. Therefore UCP 2 inhibitors, while possibly useful for treating $\beta$ cell dysfunction in the short term, could negatively affect $\beta$ cell mass in the long term. However, many pieces of evidence argue against such a view. (a) UCP2 KO mice, despite having increased mitochondrial superoxide production, maintain improved glucose homeostasis (8), even at an advanced age (12 months; C.-Y. Zhang, unpublished data). Of note, the islets of UCP2 KO mice do not have decreased DNA content compared with WT islets, indicating that there is no net loss in $\beta$ cell number (Table 1). (b) $o b / o b$ mice lacking UCP2, despite having elevated mitochondrial superoxide production in their islets as we show here show improved glucose homeostasis, even at 6 months of age (C.-Y. Zhang, unpublished data). Importantly, DNA content is unchanged between islets isolated from $o b / o b$ mice and from $o b / o b$ mice lacking UCP2 (Table 1), indicating that there is no net loss of $\beta$ cells in islets lacking UCP2. (c) Mice lacking UCP2, when fed a high-fat diet for 4.5 months, have enhanced $\beta$ cell responsiveness to glucose challenges and preserved islet sensitivity to glucose (44). This is in spite of the likely increase in mitochondrial superoxide production in the $\beta$ cells of these mice. Furthermore, the islets of UCP2 KO mice on a high-fat diet do not show signs of $\beta$ cell loss, as assessed by islet morphological analyses (44). In conclusion, increased mitochondrial superoxide production following UCP2 deficiency does not, per se, affect $\beta$ cell survival. On the surface, this may seem to be at odds with other studies showing that oxidative stress causes $\beta$ cell dysfunction, increased apoptosis, and consequent loss of $\beta$ cell mass. The reasons for this paradox are not known at this point. One may presume, however, that either the increased mitochondrial superoxide production observed in UCP2 KO mice is too low to cause deleterious effects in $\beta$ cells, or the increase in mitochondrial superoxide may not result in increased ROS in the relevant cellular compartment responsible for ROS-mediated toxicity.

The precise mechanism by which superoxide activates UCP2 remains to be elucidated. We considered $\mathrm{H}_{2} \mathrm{O}_{2}$ as a potential mediator in the superoxide-UCP2 pathway, because $\mathrm{H}_{2} \mathrm{O}_{2}$ is the immediate dismutation product of superoxide, and because it has been previously reported that $\mathrm{H}_{2} \mathrm{O}_{2}$, when added exogenously to isolated islets and $\beta$ cells, inhibits insulin secretion $(43,52,53)$. Addition of exogenous $\mathrm{H}_{2} \mathrm{O}_{2}$ to isolated islets in the range between 0 and $200 \mu \mathrm{M}$ suppressed GSIS in a dosedependent manner (data not shown), consistent with previous reports $(43,52)$. Loss of GSIS following $\mathrm{H}_{2} \mathrm{O}_{2}$ addition occurred with the same dose dependence in WT and UCP2 $\mathrm{KO}$ islets, indicating that exogenously added $\mathrm{H}_{2} \mathrm{O}_{2}$ inhibits insulin secretion in a UCP2-independent fashion. The importance of these results for hyperglycemia-induced $\beta$ cell dysfunction remains unclear, given that removal of endogenous $\mathrm{H}_{2} \mathrm{O}_{2}$ by overexpression of GPX1, which reduced total ROS in isolated islets by $50 \%$ (data not shown), did not restore hyperglycemiainduced loss of glucose sensing. Therefore, we conclude that, unlike endogenous superoxide, endogenous $\mathrm{H}_{2} \mathrm{O}_{2}$ per se does not play an integral role in mediating hyperglycemia-induced impairment of GSIS.

In conclusion, our results show that superoxidedependent activation of UCP2 has important consequences for cellular energy metabolism, notably lowering mitochondrial membrane potential and, subsequently, ATP levels. In pancreatic $\beta$ cells, this has important negative effects on GSIS. The present study clearly demonstrates that superoxide, or some downstream product, is a pathophysiologically relevant negative regulator of insulin secretion, and that activation of UCP2 by superoxide could be an important mechanism contributing to the pathogenesis of type 2 diabetes. Thus, inhibition of UCP2 activity may provide a viable strategy to improve $\beta$ cell dysfunction in type 2 diabetes. Based on studies in UCP2 KO mice $(8,44)$, such improvement is likely to occur without compromising $\beta$ cell survival. Finally, as UCP homologs are widely distributed, we hypothesize that superoxidemediated activation of UCP2 (or UCP3) and the associated depletion in cellular ATP could have implications for other pathologies associated with increased superoxide production, such as ischemia/reperfusion injury in heart, brain, and other tissues.

\section{Acknowledgments}

This work was supported by grants from the NIH (to B.B. Lowell) and the American Diabetes Association (to C.-Y. Zhang). L. Scorrano is a Human Frontier Science Program fellow. J. St-Pierre is the recipient of a Jane Coffin Childs-Merck fellowship. L.T. Dalgaard is the recipient of a postdoctoral fellowship from the Danish Medical Research Council.

\footnotetext{
1. Matthews, D.R., and Clark, A. 1997. B-cell defects and pancreatic abnormalities in non-insulin-dependent diabetes mellitus. In Textbook of diabetes. J.C. Pickup and G. Williams, editors. Blackwell Science. Oxford, United Kingdom. 21:21-16.

2. Poitout, V., and Robertson, R.P. 2002. Minireview. Secondary beta-cell failure in type 2 diabetes: a convergence of glucotoxicity and lipotoxicity. Endocrinology. 143:339-342.

3. Robertson, R.P., et al. 2000. Glucose toxicity of the beta cell: cellular and molecular mechanisms. In Diabetes mellitus. A fundamental and clinical text. D. Le Roith, S. Taylor, and J.M. Olefsky, editors. Lippincott Williams \& Wilkins. Philadelphia, Pennsylvania, USA. 125-132.

4. Jaburek, M., et al. 1999. Transport function and regulation of mitochondrial uncoupling proteins 2 and 3. J. Biol. Chem. 274:26003-26007.
} 
5. Echtay, K.S., Winkler, E., Frischmuth, K., and Klingenberg, M. 2001. Uncoupling proteins 2 and 3 are highly active $\mathrm{H}(+)$ transporters and highly nucleotide sensitive when activated by coenzyme Q (ubiquinone). Proc. Natl. Acad. Sci. U. S. A. 98:1416-1421.

6. Echtay, K.S., et al. 2002. Superoxide activates mitochondrial uncoupling proteins. Nature. 415:96-99.

7. Krauss, S., Zhang, C.Y., and Lowell, B.B. 2002. A significant portion of mitochondrial proton leak in intact thymocytes depends on expression of UCP2. Proc. Natl. Acad. Sci. U. S. A. 99:118-122.

8. Zhang, C.Y., et al. 2001. Uncoupling protein-2 negatively regulates insulin secretion and is a major link between obesity, beta cell dysfunction, and type 2 diabetes. Cell. 105:745-755.

9. Chan, C.B., et al. 2001. Increased uncoupling protein-2 levels in beta-cells are associated with impaired glucose-stimulated insulin secretion: mechanism of action. Diabetes. 50:1302-1310.

10. Patane, G., et al. 2002. Role of ATP production and uncoupling protein-2 in the insulin secretory defect induced by chronic exposure to high glucose or free fatty acids and effects of peroxisome proliferator-activated receptor-gamma inhibition. Diabetes. 51:2749-2756.

11. Laybutt, D.R., et al. 2002. Genetic regulation of metabolic pathways in beta-cells disrupted by hyperglycemia. J. Biol. Chem. 277:10912-10921.

12. Nishikawa, T., et al. 2000. Normalizing mitochondrial superoxide production blocks three pathways of hyperglycaemic damage. Nature. 404:787-790.

13. Yerneni, K.K., Bai, W., Khan, B.V., Medford, R.M., and Natarajan, R. 1999. Hyperglycemia-induced activation of nuclear transcription factor kappaB in vascular smooth muscle cells. Diabetes. 48:855-864.

14. Brownlee, M. 2001. Biochemistry and molecular cell biology of diabetic complications. Nature. 414:813-820.

15. Trocino, R.A., et al. 1995. Significance of glutathione depletion and oxidative stress in early embryogenesis in glucose-induced rat embryo culture. Diabetes. 44:992-998.

16. Tanaka, Y., Tran, P.O., Harmon, J., and Robertson, R.P. 2002. A role for glutathione peroxidase in protecting pancreatic beta cells against oxidative stress in a model of glucose toxicity. Proc. Natl. Acad. Sci. U. S. A. 99:12363-12368

17. Bindokas, V.P., et al. 2003. Visualizing superoxide production in normal and diabetic rat islets of langerhans. J. Biol. Chem. 278:9796-9801.

18. Buttgereit, F., Grant, A., Muller, M., and Brand, M.D. 1994. The effects of methylprednisolone on oxidative phosphorylation in ConcanavalinA-stimulated thymocytes. Top-down elasticity analysis and control analysis. Eur. J. Biochem. 223:513-519.

19. Brand, M.D. 1995. Measurement of mitochondrial proton motive force. In Mitochondria: a practical approach. G.C. Brown, editor. Oxford University Press. Oxford, United Kingdom. 39-62.

20. Thomas, D.A., Scorrano, L., Putcha, G.V., Korsmeyer, S.J., and Ley, T.J. 2001. Granzyme B can cause mitochondrial depolarization and cell death in the absence of BID, BAX, and BAK. Proc. Natl. Acad. Sci. U. S. A 98:14985-14990.

21. Du, X.L., et al. 2000. Hyperglycemia-induced mitochondrial superoxide overproduction activates the hexosamine pathway and induces plasminogen activator inhibitor-1 expression by increasing Sp1 glycosylation. Proc. Natl. Acad. Sci. U. S. A. 97:12222-12226.

22. Li, S., Yan, T., Yang, J.Q., Oberley, T.D., and Oberley, L.W. 2000. The role of cellular glutathione peroxidase redox regulation in the suppression of tumor cell growth by manganese superoxide dismutase. Cancer Res. 60:3927-3939.

23. Detimary, P., Jonas, J.C., and Henquin, J.C. 1995. Possible links between glucose-induced changes in the energy state of pancreatic B cells and insulin release. Unmasking by decreasing a stable pool of adenine nucleotides in mouse islets. J. Clin. Invest. 96:1738-1745.

24. Detimary, P., Jonas, J.C., and Henquin, J.C. 1996. Stable and diffusible pools of nucleotides in pancreatic islet cells. Endocrinology. 137:4671-4676.

25. Kim, Y.B., Shulman, G.I., and Kahn, B.B. 2002. Fatty acid infusion selectively impairs insulin action on Akt1 and protein kinase C lambda/zeta but not on glycogen synthase kinase-3. J. Biol. Chem. 277:32915-32922.

26. Dussmann, H., Kogel, D., Rehm, M., and Prehn, J.H. 2003. Mitochondrial membrane permeabilization and superoxide production during apoptosis. A single-cell analysis. J. Biol. Chem. 278:12645-12649.

27. Bailey, C.J., and Flatt, P.R. 1997. Animal syndromes of non-insulindependent diabetes mellitus. In Textbook of diabetes. J.C. Pickup and G. Williams, editors. Blackwell Science. Oxford, United Kingdom. 23.21-23.25.

28. Flatt, P.R., and Bailey, C.J. 1981. Development of glucose intolerance and impaired plasma insulin response to glucose in obese hyperglycaemic (ob/ob) mice. Horm. Metab. Res. 13:556-560

29. Couplan, E., et al. 2002. No evidence for a basal, retinoic, or superoxideinduced uncoupling activity of the uncoupling protein 2 present in spleen or lung mitochondria. J. Biol. Chem. 277:26268-26275.

30. Echtay, K.S., Murphy, M.P., Smith, R.A., Talbot, D.A., and Brand, M.D. 2002. Superoxide activates mitochondrial uncoupling protein 2 from the matrix side. Studies using targeted antioxidants. J. Biol. Chem. 277:47129-47135.

31. Krauss, S., Buttgereit, F., and Brand, M.D. 1999. Effects of the mitogen concanavalin A on pathways of thymocyte energy metabolism. Biochim. Biophys. Acta. 1412:129-138.

32. Patel, M., and Day, B.J. 1999. Metalloporphyrin class of therapeutic catalytic antioxidants. Trends Pharmacol. Sci. 20:359-364.

33. Negre-Salvayre, A., et al. 1997. A role for uncoupling protein-2 as a regulator of mitochondrial hydrogen peroxide generation. FASEB $J$. 11:809-815.

34. Duval, C., et al. 2002. Increased reactive oxygen species production with antisense oligonucleotides directed against uncoupling protein 2 in murine endothelial cells. Biochem. Cell Biol. 80:757-764.

35. Arsenijevic, D., et al. 2000. Disruption of the uncoupling protein-2 gene in mice reveals a role in immunity and reactive oxygen species production. Nat. Genet. 26:435-439.

36. Vidal-Puig, A.J., et al. 2000. Energy metabolism in uncoupling protein 3 gene knockout mice. J. Biol. Chem. 275:16258-16266.

37. Bjorklund, A., Lansner, A., and Grill, V.E. 2000. Glucose-induced [Ca2+]i abnormalities in human pancreatic islets: important role of overstimulation. Diabetes. 49:1840-1848.

38. Marshak, S., et al. 1999. Impaired beta-cell functions induced by chronic exposure of cultured human pancreatic islets to high glucose. Diabetes. 48:1230-1236.

39. Kaneto, H., et al. 1999. Beneficial effects of antioxidants in diabetes: possible protection of pancreatic beta-cells against glucose toxicity. Diabetes. 48:2398-2406.

40. Ihara, Y., et al. 1999. Hyperglycemia causes oxidative stress in pancreatic beta-cells of GK rats, a model of type 2 diabetes. Diabetes. 48:927-932.

41. Xu, B., Moritz, J.T., and Epstein, P.N. 1999. Overexpression of catalase provides partial protection to transgenic mouse beta cells. Free Radic. Biol. Med. 27:830-837.

42. Kubisch, H.M., Wang, J., Bray, T.M., and Phillips, J.P. 1997. Targeted overexpression of $\mathrm{Cu} / \mathrm{Zn}$ superoxide dismutase protects pancreatic beta-cells against oxidative stress. Diabetes. 46:1563-1566.

43. Sakai, K., et al. 2003. Mitochondrial reactive oxygen species reduce insulin secretion by pancreatic beta-cells. Biochem. Biophys. Res. Commun. 300:216-222

44. Joseph, J.W., et al. 2002. Uncoupling protein 2 knockout mice have enhanced insulin secretory capacity after a high-fat diet. Diabetes. 51:3211-3219.

45. Koshkin, V., Wang, X., Scherer, P.E., Chan, C.B., and Wheeler, M.B. 2003. Mitochondrial functional state in clonal pancreatic beta-cells exposed to free fatty acids. J. Biol. Chem. 278:19709-19715

46. Medvedev, A.V., et al. 2002. Regulation of the uncoupling protein-2 gene in INS-1 beta-cells by oleic acid. J. Biol. Chem. 277:42639-42644.

47. Lameloise, N., Muzzin, P., Prentki, M., and Assimacopoulos-Jeannet, F. 2001. Uncoupling protein 2: a possible link between fatty acid excess and impaired glucose-induced insulin secretion? Diabetes. 50:803-809.

48. Below-Chain, A., Freund, N., and Rookledge, K.A. 1975. Blood glucose and serum insulin levels in lean and genetically obese mice. Horm. Metab. Res. 7:374-378

49. Brichard, S.M., Bailey, C.J., and Henquin, J.C. 1990. Marked improvement of glucose homeostasis in diabetic ob/ob mice given oral vanadate. Diabetes. 39:1326-1332.

50. Papa, S., and Skulachev, V.P. 1997. Reactive oxygen species, mitochondria, apoptosis and aging. Mol. Cell. Biochem. 174:305-319.

51. Brand, M.D., et al. 2002. Oxidative damage and phospholipid fatty acyl composition in skeletal muscle mitochondria from mice underexpressing or overexpressing uncoupling protein 3. Biochem. J. 368:597-603

52. Maechler, P., Jornot, L., and Wollheim, C.B. 1999. Hydrogen peroxide alters mitochondrial activation and insulin secretion in pancreatic beta cells. J. Biol. Chem. 274:27905-27913.

53. Krippeit-Drews, $\mathrm{P}$, et al. 1999. Interference of $\mathrm{H} 2 \mathrm{O} 2$ with stimulus-secretion coupling in mouse pancreatic beta-cells. J. Physiol. 514:471-481.

54. Hou, X., et al. 1999. Prolonged exposure of pancreatic beta cells to raised glucose concentrations results in increased cellular content of islet amyloid polypeptide precursors. Diabetologia. 42:188-194. 